Article

\title{
Relationship between Rural Settlements' Plant Communities and Environmental Factors in Hilly Area of Southeast China
}

\author{
Ziyan Wang ${ }^{1,2,3}$, Cheng Wang ${ }^{2,3, *}$, Zehui Jiang ${ }^{1, *}$, Tao Hu ${ }^{1}$, Wenjing Han ${ }^{2,3}$, Chang Zhang ${ }^{2,3}$, \\ Jiali Jin ${ }^{2,3}$, Kaiyue Wei ${ }^{2,3}$, Jiao Zhao ${ }^{2,3}$ and Xinyu Wang ${ }^{2,3}$ \\ 1 International Centre for Bamboo and Rattan, National Forestry and Grassland Administration Key \\ Laboratory of Bamboo and Rattan, Beijing 100102, China; ziyanw@icbr.ac.cn (Z.W.); hutao@icbr.ac.cn (T.H.) \\ 2 Research Institute of Forestry, Chinese Academy of Forestry, Beijing 100091, China; \\ hanwenjing@caf.ac.cn (W.H.); song.yan.zheng@163.com (C.Z.); king90emily@gmail.com (J.J.); \\ wkaiyuewei@163.com (K.W.); zhaojiao226419@163.com (J.Z.); wangxinyu1459@163.com (X.W.) \\ 3 Urban Forest Research Center, National Forestry and Grassland Administration, Beijing 100091, China \\ * Correspondence: wch8361@163.com (C.W.); zhjiang2015@163.com (Z.J.)
}

Received: 12 February 2020; Accepted: 28 March 2020; Published: 1 April 2020

check for updates

\begin{abstract}
The construction of the ecological environment in rural settlements is a very important part of the development of human settlements. Key to this construction is the coordinated and sustainable development of plant environment, geographical environment, and human activities. Therefore, it is necessary to study the characteristics of plant diversity and their driving mechanisms. The study area, 'Shanchuan Town', is located in the hilly area of Southeast China, Anji County, Zhejiang Province. As bamboo forests cover $62 \%$ of the total forests, it has the reputation of being the "China town of bamboo". To interpret rural plant community features, we extracted topography data by the field survey, satellite image, and Digital Elevation Model (DEM) based on ArcGIS platform, then used Spearman's correlation and a redundancy analysis to examine the relationships between explanatory variables (e.g., plot elevation, slope aspect and architectural height, etc.) and the distribution of plant community diversity. In this study, 227 plots were selected from 14 settlements to investigate totally $105,88,206$, and 17 species of trees, shrubs, herbs, and vines, respectively, belonging to 147 families, 324 genera, and 416 species. Among them, there were 19 bamboo species, and 47 species of alien plants, which accounted for $11.3 \%$ of the total. The dominant trees and shrubs were mainly native species with high edible or ornamental value. The dominant bamboo species were common species for bamboo shoots in Zhejiang Province, while most of the dominant herbaceous species were alien species. Among the explanatory variables, the impact of plot elevation (PE) on plant community was significantly higher than those of other explanatory factors. The correlation analysis showed that the richness and diversity indices of different plant life layers were significantly related to PE. Among the architectural factors, the architectural orientation (AO) and layout type (AT) effect on shrubs and other herbaceous species was stronger than those on trees and bamboo. There was a high plant community richness in the study area, and both topography and architectural factors had a significant effect on plant community. Therefore, construction of the plant landscape should conform to the topography and regulate the residential construction activities properly, so as to get rid of urban planning thinking and the excessive pursuit of plant diversity, realizing the sustainable development of ecological environment in settlements.
\end{abstract}

Keywords: rural settlements; plant diversity; hilly area; plant distribution pattern; ecological environment construction 


\section{Introduction}

Settlements in the residential areas are not only the basic unit of interaction between human beings and other landscape elements, but also an essential geographical division from other land use types, such as farmlands [1-3]. The ecological construction of rural settlements is quite essential as a part of human settlements. Moreover, it is also a core issue in the study of ecologically sustainable human settlements. In particular, exploring the mechanism of environmental influence on plants including human activities is an important part to solve ecological problems. Although the environmental construction in rural areas has been valued, it has also been disturbed by high levels of non-residents. The application of an urban planning method does not have a positive impact on the sustainable development of rural areas, which have lost their own cultural landscape attributes, owing to homogenization, and failed to meet the actual needs of residents in China. In particular, in human settlements, the plant communities that integrate ecological and economic value constitute the ecological environment with a closest relation to human living activities, i.e., plants meet most daily-life needs for residents, and residents' activities are important factors affecting the sustainability of the ecosystem [4]. Therefore, different distribution patterns of plant community gradually appeared under the combined effects of the geographical environment and human activities. In addition, the difference on planting and plant utilization in settlements at the individual level also shows the importance of plant diversity to the "Ecology and Culture" of sustainable human settlements and people's attention to biodiversity $[5,6]$.

Several studies have focused on the diversity characteristics of settlement plant communities and their influencing factors, ethnobotany of settlement, and the optimization of human ecological landscape construction, domestically and overseas [7]. In terms of policy, the construction of beautiful villages proposed by the Chinese authority is an important approach to rural revitalization in China [8]. The sustainable development of rural settlements is inseparable from the construction of the plant landscape. Research on species diversity and the protection of biological diversity from the perspective of landscape planning is a key research direction in rural landscapes, and it has also been a research hotspot [9]. Although the ecological environment of rural settlements is strongly disturbed by human beings, including residents, planners, and tourists, it still retains more natural ecological landscapes than that in cities, and its natural and cultural environment is better than that from completely planning. Therefore, it is very meaningful to study the community diversity and its relationship with the environment in the hilly area of Southeast China (hereafter referred to as the hilly area). Specifically, researches on plant community distribution included the spatial-temporal dynamic changes of plants and other types of patches in large-scale rural areas $[10,11]$. There was also extensive research on the impact of land use and topography to the distribution of plants in rural settlements [12]. Moreover, Geographic Information System (GIS) and Urban Microclimate Simulation Tool (ENVI-met) analysis of plant spatial distribution in settlement units and spatial-temporal dynamic change analysis of microclimate are used at a smaller scale [13].

Within the scope of China's comprehensive consideration of natural environmental factors and human activities, research on the distribution of alien invasive plants showed that both factors affect plants (i.e., environmental features and human activity intensity). Both factors contribute to a comprehensive understanding of the distribution patterns of the country's plant communities, which were closely related to residents, ecological planning and the future of scientific prediction [14]. However, the mechanism and relative influence of environment and human activities on plant community at a small scale in the hilly area remain unknown.

Bamboo plants have important ecological and economic functions in the hilly area, which are indispensable for the sustainable development of rural settlements. Shanchuan Town. It is a typical residential settlement with hilly characteristics, and a key town for tourism, because of its superior geographical location, rich tourism, bamboo resources, and first-class air quality. Thus, it is known as the natural oxygen bar [15]. This study focused on the biological environment in the settlements and discussed the impact of human activities and topographic characteristics on plant communities in Shanchuan Town of Anji Country, Zhejiang Province, a typical residential community with hilly 
characteristics. The study focused on the distribution, diversity, and ethnobotanical characteristics of bamboo in the residential environment of the settlement, as well as the influence mechanism of topography and architectural variables on different layers of the plant community.

Many influencing factors can be selected, including local residents' life, interference by tourists', topography, climate, soil, community structure, etc. [16] This study mainly considers the topography and architecture of buildings. The topography factors, including slope, aspect and elevation, have a significant impact on the distribution pattern of forest communities and settlements in the mountain area. This study hypothesizes that even in ecological environments with strong human disturbance, the topography factors are still an important factor for the distribution of plant communities. In addition, the distance to the center of the residential unit is used to discuss the relationship between the environment and the distribution pattern and diversity of plant communities. Regarding architectural factors, the most obvious aspect of human disturbance is residential construction activity, which is the construction that residents are most concerned about. In this study, architectural attributes are used to represent the disturbance of human residential activities. Architectural variables, such as average height (AH), style (AS), layout type (AT), function (AF), and courtyard enclosure type (GT) were selected to analyze the diversity of plant communities caused by human activities.

In human settlements, the factors influencing plant communities are more complex than those of natural forest communities. This study selected the aforementioned variables, to quantitatively analyze the relationship between plant community and the environment in the settlements in coastal hilly areas of China, to assess which factor has a higher explanation ability under mixed external disturbances and the correlation mechanism between studied variables and plant community diversity. This study addresses (1) the characteristics of dominant species in the plant community of rural settlements in hilly areas and (2) the effects of environmental explanatory variables on plant communities, and (3) suitable suggestions for the sustainable development of the settlement plant environment. Understanding the plant community characteristics and influencing factors in the settlements of hilly areas is important to guide the planning of hilly settlement plants and tourism construction scientifically. Rather than simply applying the construction model of the urban plant landscape to make the rural plant environment construction of poor quality, this paper contributes to the understanding of the ecological value of the construction of human settlements, in China and worldwide.

\section{Materials and Methods}

\subsection{Study Area}

The study area was located in Zhejiang Province, in the coast of southeastern China, covering an area of $105,500 \mathrm{~km}^{2}$. The topographic slopes are, stepwise, from southwest to northeast. The southwest part is dominated by mountains, while the central part is dominated by hills. The northeast part is a low flat alluvial plain, in which mountains and hills account for $74.63 \%$ of the area, flat land for $20.32 \%$, and rivers and lakes for the remaining 5.05\%. Zhejiang Province is located in the subtropical evergreen broad-leaved forest belt, with subtropical monsoon climate, and average annual temperature and precipitation of $15-18{ }^{\circ} \mathrm{C}$ and $980-2000 \mathrm{~mm}$, respectively, abundant light and rainfall, ample vegetation resources, high forest coverage, bamboo area, and number of trees. Regarding rural construction, Zhejiang Province includes 24 counties designated as National leisure agriculture and rural tourism demonstration sites, 8 important agricultural cultural heritage sites, and 36 beautiful leisure villages. In total, 8 heritage sites, 36 beautiful leisure villages and 1162 villages, mainly for tourism, have been built. Moreover, 100 beautiful rural demonstration towns and 300 boutique villages have been cultivated and created during the process of village construction in Zhejiang province (Zhejiang Provincial Bureau of statistics, 2018).

In this study, we selected the vanguard town of beautiful rural construction, Shanchuan Town, which is located in the hilly area in the northwest of Zhejiang Province. This bamboo forest area belongs to the mountainous bamboo forest ecological area in the northwest of Zhejiang Province [17], 
with a total administrative area of $46.72 \mathrm{~km}^{2}$ and six administrative villages under its jurisdiction. It is located at $30^{\circ} 26^{\prime} \mathrm{N}$ and $119^{\circ} 39^{\prime} \mathrm{E}$, with a vegetation coverage of $91.3 \%$. Forest coverage is $88.8 \%$, and the bamboo forest area ( $2533.3 \mathrm{ha}$ ) accounts for $62 \%$ of the forest coverage area.

In this study, 14 settlements in Shanchuan Town were selected (Figure 1), and the settlement boundary (building or road boundary) was drawn, with 100 or $30 \mathrm{~m}$ as the maximum length, following $\mathrm{Pu}$ Xincheng's definition [18]. Moreover, $30 \mathrm{~m}$ was buffered outwards as the actual extents of settlement research areas, including buildings, plant communities in the settlement, and forests in the periphery of the settlement.

(a)

(b)
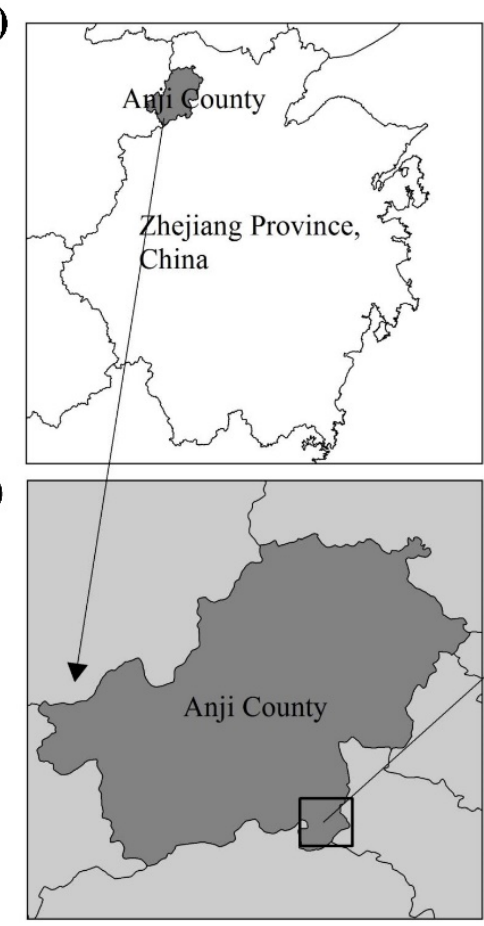

(c)

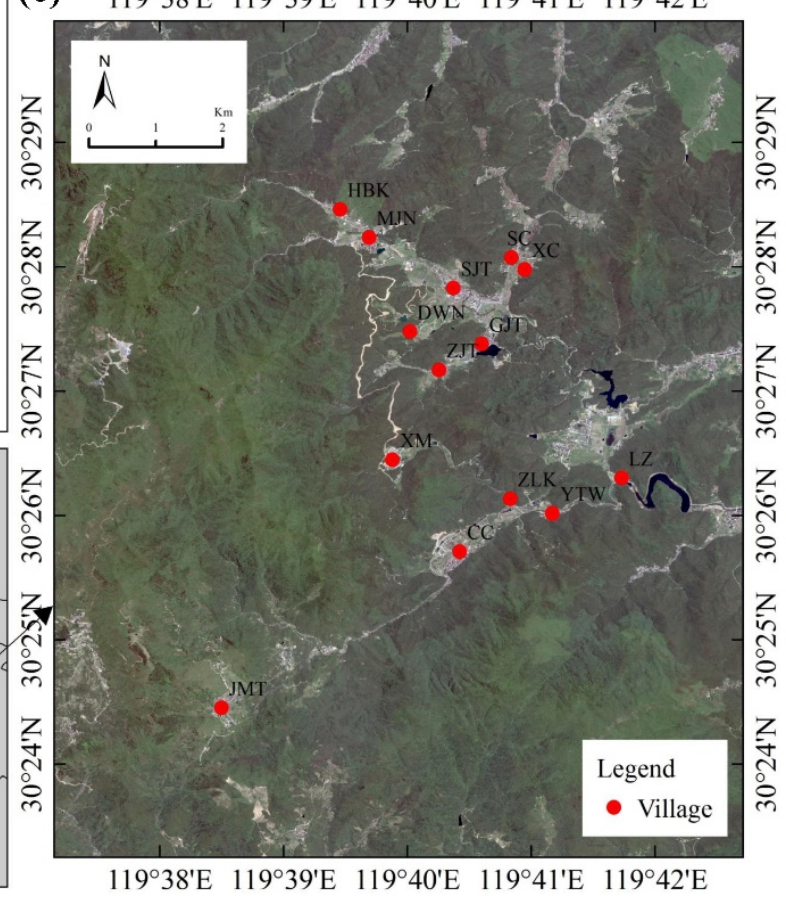

Figure 1. (a) Map of Zhejiang Province, China (Source: National Geomatics Centre of China). (b) Scope of Anji County $\left(119^{\circ} 37^{\prime}-119^{\circ} 40^{\prime} \mathrm{E}, 30^{\circ} 24^{\prime}-30^{\circ} 29^{\prime} \mathrm{N}\right)$, with the black rectangle representing Shanchuan Town (Source: National Geomatics Centre of China). (c) Aerial image of Shanchuan Town, with the red circle representing 14 settlements (Source: Google Earth Image).

\subsection{Data Collection}

All sampling that was done to investigate trees, shrubs, herbs, and vines in the study area was carried out in April of 2019. In particular, we classified the bamboo plants independently from the herbs and calculated the importance value and diversity index of bamboo plants, based on the regional characteristics of the background of the bamboo countryside in the hilly areas of China. The sampling included the plant communities closely related to the living environment of rural settlements, such as the front and back of houses and the surrounding of settlements, excluding crop plants, such as vegetable land behind the house, or large area of orchard forest land around the settlement. Taking the plant distribution as a reference, we sampled plots $(40 \times 40 \mathrm{~m}$ quadrat, 227 sample plots in total $)$ in the same way. In each sample plot, we recorded all tree species in a $5 \times 5 \mathrm{~m}$ plot, recording the names, spatial locations, numbers of trees, heights and diameters of the plants at breast height. Shrub and bamboo species were counted in the $5 \times 5 \mathrm{~m}$ plot. Other herbaceous species were counted in each $1 \times 1 \mathrm{~m}$ plot, recording the species, spatial locations, numbers (or coverage area) and heights of shrubs, bamboos, or herbs [19]. At the same time, we recorded the specific information of architectural style (AS), orientation (AO), height (AH), layout type (AT), function (AF) and garden type (GT) of the sample plot. The study used the 0.3-m high-resolution satellite image (Google Earth Image) of September 2018, 
Anji vector boundary map, digital elevation model (DEM) map (Aster GDEM at $30 \mathrm{~m}$ resolution), and geospatial data cloud website of 14 settlement residential units. Using ArcGIS 10.2 (ESRI, Redlands, CA, USA) software and the field survey, we interpreted and explained the coverage and distribution of buildings, roads, water bodies, plants, and other elements in the settlement, extracting the elevation of sample center (PE), slope (PS), slope aspect (PSA), and the linear distance between the sample plot and geometric center of settlement (DFC), that were calculated from the DEM data.

Table 1 shows that the four topographic factors are all continuous variable, and most of architectural factors are categorical variable, except for architecture height (AH), which is the average height of buildings contained in the plot. Specifically, architectural style (AS) included traditional, modern and combined style; traditional houses were always old ones, and modern houses were relatively new. Architecture orientations (AO) were classified as 8 aspects. Architecture layout type (AT) was the planar texture of the building, including long house, L-shape house and single house, etc. Meanwhile, architecture function (AF) included houses for tourism, public buildings and abandoned buildings, etc. Garden types (GT) were classified as 4 categories, dependent on the enclosure form.

Table 1. Environment explanatory variables.

\begin{tabular}{|c|c|c|c|}
\hline & Variables & Definition & Variable Type \\
\hline \multirow{4}{*}{ Topography } & Plot Elevation $(\mathrm{PE})(\mathrm{M})$ & - & Continuous Variable \\
\hline & Plot Slope (PS) $\left(^{\circ}\right)$ & - & Continuous Variable \\
\hline & Plot Slope Aspect (PSA) & - & Continuous Variable \\
\hline & $\begin{array}{l}\text { Deviation from Center of } \\
\text { Settlement (DFC) (M) }\end{array}$ & $\begin{array}{l}\text { Linear distance between sample plot } \\
\text { and geometric center of settlement }\end{array}$ & Continuous Variable \\
\hline \multirow{6}{*}{ Architecture } & Architecture Style (AS) & $\begin{array}{l}\text { Traditional house, Modern house, } \\
\text { Combined house }\end{array}$ & Categorical Variable \\
\hline & $\begin{array}{l}\text { Architecture Height } \\
\quad(\mathrm{AH})(\mathrm{M})\end{array}$ & $\begin{array}{l}\text { Average height of the buildings } \\
\text { contained in the sample }\end{array}$ & Continuous Variable \\
\hline & $\begin{array}{l}\text { Architecture Orientation } \\
\text { (AO) }\end{array}$ & $\begin{array}{l}\text { North, Northeast, East, Southeast, } \\
\text { South, Southwest, West, Northwest }\end{array}$ & Categorical Variable \\
\hline & $\begin{array}{l}\text { Architecture Layout } \\
\text { Type (AT) }\end{array}$ & $\begin{array}{l}\text { Single house, L-shaped house, Long } \\
\text { house, Three-section compound } \\
\text { house }\end{array}$ & Categorical Variable \\
\hline & $\begin{array}{l}\text { Architecture Function } \\
\text { (AF) }\end{array}$ & $\begin{array}{l}\text { Self-occupied house, Homestay, } \\
\text { Public buildings, Buildings under } \\
\text { construction, Abandoned buildings }\end{array}$ & Categorical Variable \\
\hline & Garden Type (GT) & $\begin{array}{l}\text { Enclosed type, Semi-enclosed type, } \\
\text { No enclosed type, no courtyard }\end{array}$ & Categorical Variable \\
\hline
\end{tabular}

\subsection{Analysis of Vegetation Data}

The importance value of trees, shrubs, and herbs ( $\mathrm{IV}_{\text {tree, }} \mathrm{IV}_{\text {shrub}}$, and $\mathrm{IV}_{\text {herb }}$ respectively) were calculated as

$\mathrm{IV}_{\text {tree }}(\%)=($ relative abundance + relative significance + relative frequency $) / 3 ;$

$\mathrm{IV}_{\text {shrub }}(\%)=($ relative abundance + relative coverage + relative frequency $) / 3 ;$

$\operatorname{IV}_{\text {herb }}(\%)=($ relative coverage + relative frequency $) / 2 ;$ where;

relative abundance $(\%)=100 \times$ the number of trees of a certain species/the total number of trees of all species;

relative significance $(\%)=100 \times$ base diameter cross-sectional area of a certain species/total base diameter cross-sectional area of all species.

relative frequency $(\%)=100 \times$ frequency of a certain species/ the total frequency of all species; relative coverage $(\%)=100 \times$ the coverage of a certain species/the total coverage of all species Additionally, the number of species in the community ( $\mathrm{S}$ or R; Patrick richness index) and other diversity indices were calculated,

Shannon-Wiener Index $(\mathrm{H})=-\sum \mathrm{P} i \operatorname{lnP} i$;

Pielou Evenness Index $(\mathrm{J})=H / \mathrm{Ln} S$; 
where Pi represents the proportion of the number of individuals of the $\mathrm{i}^{\text {th }}$ species relative to the total number of individuals in the sample [19].

\subsection{Statistical Analysis}

The Kolmogorov-Smirnov (K-S) test was used to test if data of the variables follow normal distributions (e.g., elevation, slope, and architecture style and etc.) The results showed that the gradual significance (two-tail tests) was less than 0.05 , so the data did not conform to the normal distribution. Therefore, we selected Spearman correlation analysis, which is a non-parametric method for measuring correlations between variables of ranked orders. In addition, linear regression and other regression had been tried but did not perform well, and therefore we used spearman's rank correlation. Without considering the interaction of multiple factors, we performed a pairwise correlation analysis between the explanatory variables and the diversity index of different plants, as well as the correlation analysis between explanatory variables.

A redundancy analysis (RDA) was used to analyze the impact of environmental variables, including topographic and architectural variables on the overall plant community distribution pattern in hilly settlements. A preliminary detrended correspondence analysis (DCA), performed on the transformed species data of 227 samples, revealed a gradient length of 2.39 along the first axis, suggesting that redundancy analysis (RDA) was appropriate. We performed RDA using the function rda, and tested the significance using the Monte Carlo test $(p<0.001)$, to obtain believable results [20].

Statistical analyses were performed using SPSS statistics, version 25 (SPSS Inc., Chicago, USA) and $R$ version 3.6.2 ( $R$ core team, Vienna, Austria), including package vegan for ordination analysis, corrplot for correlation analysis, and ggplot2 for chart drawing.

\section{Results}

\subsection{Species and Diversity Characteristics}

\subsubsection{Composition of Families, Genus and Species}

There were 227 plots from 14 settlement units, which contained species of trees (105), shrubs (88), bamboos (19), other herbs (187) and vines (17), that belong to 147 families, 324 genera, and 416 species (19 bamboo species). There were 47 invasive species, which constitutes $11.30 \%$ in total. (Figure 2)

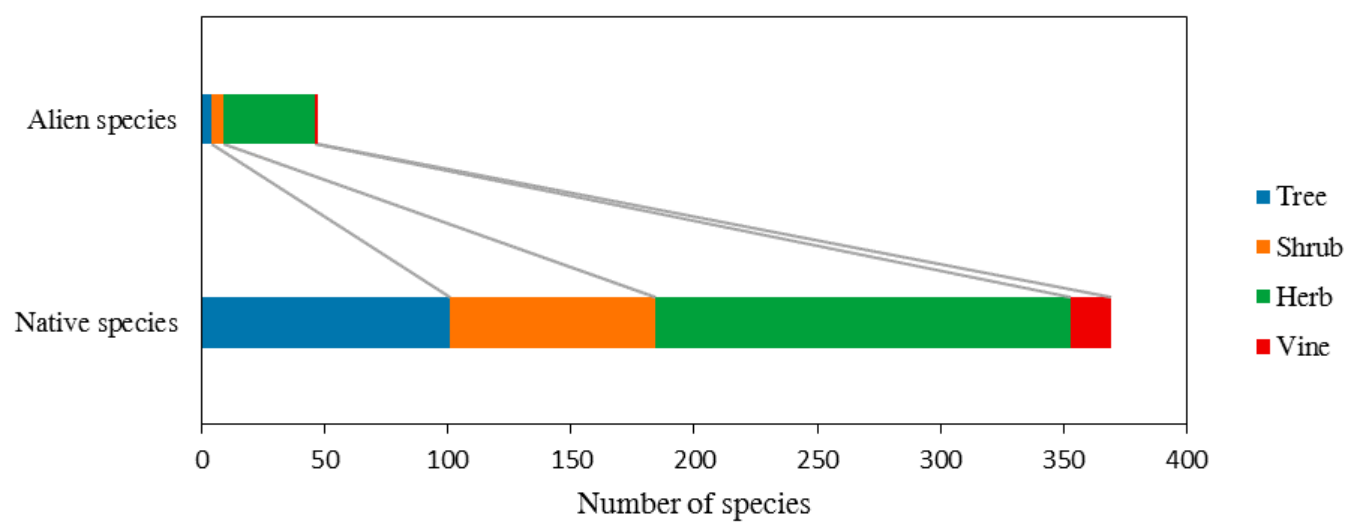

Figure 2. Number of native and alien species of different life form of plants.

Regarding the main families and genera, the trees were mainly economic fruit trees, such as Rosaceae and Leguminous. Shrubs were mainly ornamental plants, such as Rosaceae, Lonicera, and Osmanthus, while herbs were mainly Compositae and Gramineae (Table 2). 
Table 2. Main families and genera of plants in hilly settlements.

\begin{tabular}{|c|c|c|c|c|}
\hline Life Form & Families & Genera & Species & Main Species \\
\hline \multirow{3}{*}{ Tree } & Rosaceae & 8 & 13 & \multirow{3}{*}{$\begin{array}{c}\text { Pyrus,i, Eriobotrya japonica, Armeniaca vulgaris, } \\
\text { Amygdalus persica } \\
\text { Sophora japonica, Gleditsia sinensis, Robinia } \\
\text { pseudoacacia, Cercis chinensis, Sophora japonica, } \\
\text { Gleditsia sinensis, Pterocarpus indicus } \\
\text { Juniperus formosana, Platycladus orientalis, Boulevard } \\
\text { Cypress, Sabina chinensis, Platycladus orientalis, } \\
\text { Sabina chinensis }\end{array}$} \\
\hline & Leguminous & 5 & 7 & \\
\hline & Cypress & 4 & 6 & \\
\hline \multirow{3}{*}{ Shrub } & Rosaceae & 8 & 14 & \multirow{3}{*}{$\begin{array}{c}\text { Photinia serrulata, Malus spectabilis, Rubus hirsutus, } \\
\text { Rubus idaeus, Rosa rugosa, Chaenomeles sinensis, Rosa } \\
\text { Osmanthus fragrans, Ligustrum compactum, } \\
\text { Jasminum nudiflorum, Ligustrum vicaryi Forsythia } \\
\text { viridissima, Syringaoblata Lindl } \\
\text { Viburnum plicatum, Lonicera japonica, Lonicera } \\
\text { trichosantha, Abelia biflora, Abelia grandiflora, } \\
\text { Weigela florida }\end{array}$} \\
\hline & Osmanthus & 5 & 6 & \\
\hline & Lonicera & 4 & 6 & \\
\hline \multirow{4}{*}{ Herb } & Compositae & 31 & 36 & \multirow{4}{*}{$\begin{array}{c}\text { Artemisia argyi, Artemisia lactiflora, Gynura } \\
\text { divaricata, Xanthium sibiricum, Pterocypsela indica, } \\
\text { Bellis perennis, Farfugrium japonicum } \\
\text { Imperata cylindrica, Phyllostachys iridescens, } \\
\text { Pseudosasa amabilis, Lophatherum gracile, Axonopus } \\
\text { compressus, Chimonobambusa quadrangularis } \\
\text { Heracleum hemsleyanum, Apium graveolens, } \\
\text { Foeniculum vulgare, Centella asiatica, Torilis scabra, } \\
\text { Oenanthe javanica } \\
\text { Mentha haplocalyx, Clinopodium chinense, Glechoma } \\
\text { longituba, Ajuga ciliata, Ocimum basilicum, Origanum } \\
\text { vulgare, Salvia japonica, Lamium barbatum }\end{array}$} \\
\hline & Gramineae & 27 & 35 & \\
\hline & Umbels & 10 & 11 & \\
\hline & Labiate & 10 & 10 & \\
\hline
\end{tabular}

\subsubsection{Composition of Dominant Species}

According to the importance values of plants in 14 settlements, the dominant trees were mainly local ones, and they have high edible or ornamental values, which can meet the needs of residents' production, life, smell, and aesthetics. For example, the economic edible trees included those such as Ziziphus jujuba, Pyrus,i, Carya cathayensis, and Punica granatum, and the local basic greening trees such as Cinnamomum camphora, Eucommia ulmoides, Ginkgo biloba, and Metasequoia glyptostroboides. Shrubs were mainly ornamental species, such as Osmanthus fragrans, Camellia japonica, Loropetalum chinense, and Rhododendron simsii. The dominant bamboo species were common ones for bamboo shoots in Zhejiang Province, such as Phyllostachys heterocycla, Phyllostachys nuda, Phyllostachys propinqua, Phyllostachys prominens, and Phyllostachys nigra. Other herbs were dominated by alien species, such as Erigeron annuus, Veronica persica, Cerastium glomeratum and Hydrocotyle sibthorpioides.

\subsection{Diversity index Analysis}

\subsubsection{Characteristics of Diversity Index}

In the study area, the overall $H$ and $J$ values are 4.81 and 0.81 , respectively. Moreover, calculated $H$ values of different plant classes were as follows: other herbs (3.94) $>$ trees (3.67) $>$ shrubs (3.26) $>$ vines (2.40) > bamboo (2.16). J of plant communities changed slightly among different plants, $0.73-0.85$. The distribution characteristics of plant diversity at the sample level were as follows: $S$ was mainly distributed under 20, $H$ ranged between 0.5 and 3.0, and $J$ ranged between 0.7 and 1.0.

\subsubsection{Correlation between Diversity Index and Environmental Explanatory Variables}

Using the Patrick richness, Shannon-Wiener diversity, and Pielou evenness indices of trees, shrubs, bamboo, and other herbs, Spearman correlation analysis was carried out between the indices and 10 environmental explanatory variables (Table 3). 
Table 3. Spearman correlation coefficient among plant diversity indices and environment explanatory variables (Topography Variables: PE-Plot Elevation, PS-Plot slope, PSA-Plot slope aspect, DFC-Deviation from center of settlement; Architectural Variables: AF-Architecture function, AS-Architecture style, GT-Garden type, $\mathrm{AH}-$ Architecture height, $\mathrm{AO}-$ Architecture Orientation, AT—Architecture layout type; Plant Community Index: $\mathrm{S}_{\mathrm{A}}-\mathrm{Overall}$ richness index of plants, $\mathrm{H}_{\mathrm{A}}-\mathrm{Overall}$ diversity index of plants, $\mathrm{J}_{\mathrm{A}}$-Overall evenness index of plants, $\mathrm{S}_{\mathrm{T}}$-Richness index of trees, $\mathrm{H}_{\mathrm{T}}$-Diversity index of trees, $\mathrm{J}_{\mathrm{T}}-$ Evenness index of trees, $\mathrm{S}_{\mathrm{S}}-$ Richness index of shrubs, $\mathrm{H}_{\mathrm{S}}$-Diversity index of shrubs, $\mathrm{J}_{S}$-Evenness index of shrubs, $\mathrm{S}_{\mathrm{B}}$-Richness index of bamboo, $\mathrm{H}_{\mathrm{B}}$-Diversity index of bamboo, $\mathrm{J}_{B}-$ Evenness index of bamboo, $\mathrm{S}_{\mathrm{C}}$-Richness index of other herbs, $\mathrm{H}_{\mathrm{C}}$-Diversity index of other herbs, $\mathrm{J}_{\mathrm{C}}$-Evenness Index of other herbs).

\begin{tabular}{|c|c|c|c|c|c|c|c|c|c|c|c|c|c|c|c|c|}
\hline \multirow{2}{*}{ Variables } & & \multicolumn{3}{|c|}{ Total Plant Community } & \multicolumn{3}{|c|}{ Trees } & \multicolumn{3}{|c|}{ Shrubs } & \multicolumn{3}{|c|}{ Bamboo } & \multicolumn{3}{|c|}{ Other Herbs } \\
\hline & & $\mathrm{S}_{\mathrm{A}}$ & $\mathbf{H}_{\mathrm{A}}$ & $\mathbf{J}_{\mathrm{A}}$ & $\mathrm{S}_{\mathrm{T}}$ & $\mathbf{H}_{T}$ & $\mathrm{~J}_{\mathrm{T}}$ & $\mathrm{S}_{\mathrm{S}}$ & $\mathrm{H}_{\mathrm{S}}$ & $\mathrm{JS}_{\mathrm{S}}$ & $S_{B}$ & $H_{B}$ & $\mathrm{~J}_{\mathrm{B}}$ & $\mathrm{S}_{\mathrm{C}}$ & $\mathrm{H}_{\mathrm{C}}$ & $\mathrm{J}_{\mathrm{C}}$ \\
\hline \multirow{4}{*}{ Topography } & PS & $-0.219 * *$ & -0.09 & 0.042 & $-0.205^{* *}$ & -0.104 & -0.103 & $-0.174^{* *}$ & -0.091 & -0.087 & 0.033 & 0.034 & 0.044 & $-0.176 * *$ & $-0.185 * *$ & $-0.152 *$ \\
\hline & PSA & -0.04 & -0.019 & 0.038 & 0.006 & -0.025 & 0.018 & 0.022 & 0.007 & 0.001 & -0.044 & -0.062 & -0.015 & -0.101 & -0.05 & -0.033 \\
\hline & PE & $-0.202 * *$ & -0.121 & -0.039 & $-0.139 *$ & -0.015 & -0.03 & -0.12 & -0.119 & -0.08 & -0.163 * & $-0.179 * *$ & $-0.199 * *$ & $-0.146 *$ & -0.089 & -0.109 \\
\hline & DFC & -0.046 & -0.088 & 0.106 & -0.034 & 0.038 & -0.005 & -0.046 & -0.044 & -0.031 & -0.023 & 0.058 & 0.028 & -0.087 & -0.071 & -0.042 \\
\hline \multirow{6}{*}{ Architecture } & AS & 0.112 & $0.148 *$ & 0.121 & 0.107 & 0.031 & $0.176^{* *}$ & $0.132 *$ & 0.091 & 0.093 & -0.001 & 0 & 0.005 & 0.111 & 0.083 & 0.078 \\
\hline & AH & 0.037 & 0.05 & 0.122 & 0.058 & -0.025 & $0.143 *$ & 0.074 & 0.046 & 0.059 & -0.071 & -0.056 & -0.05 & 0.034 & -0.003 & 0.012 \\
\hline & AO & 0.114 & $0.170 *$ & 0.071 & 0.118 & 0.005 & 0.170 * & 0.170 * & 0.099 & 0.082 & -0.071 & -0.068 & -0.053 & 0.087 & 0.067 & 0.062 \\
\hline & AT & 0.124 & 0.091 & 0.076 & 0.129 & 0.036 & $0.185^{* *}$ & 0.119 & 0.048 & 0.069 & -0.036 & -0.037 & -0.021 & 0.102 & 0.08 & 0.082 \\
\hline & $\mathrm{AF}$ & 0.123 & 0.104 & 0.077 & 0.102 & 0.039 & $0.173^{* * *}$ & $0.159 *$ & 0.103 & 0.103 & 0.011 & 0 & 0.015 & 0.097 & 0.067 & 0.057 \\
\hline & GT & $0.165^{*}$ & $0.167^{*}$ & -0.006 & 0.12 & 0.076 & $0.162 *$ & $0.212^{* *}$ & 0.140 * & $0.150 *$ & -0.057 & -0.057 & -0.069 & $0.158^{*}$ & $0.141 *$ & 0.113 \\
\hline
\end{tabular}

* Correlation is significant at the 0.05 level (two-tailed). ${ }^{* *}$ Correlation is significant at the 0.01 level (two-tailed). 
For all samples, elevation (PE) was significantly negatively correlated with the richness of all plants $\left(S_{\mathrm{A}} ; r=-0.202, p<0.01\right)$, trees $\left(S_{\mathrm{T}} ; r=-0.139, p<0.05\right)$, bamboo plants $\left(S_{\mathrm{B}} ; r=-0.163, p<0.05\right)$, and other herbs $\left(S_{C} ; r=-0.146, p<0.05\right)$, as well as bamboo diversity $\left(H_{B} ; r=-0.179, p<0.01\right)$ and evenness $\left(J_{\mathrm{B}} ; r=-0.199, p<0.01\right)$. The slope (PS) was significantly negatively correlated with $S_{\mathrm{A}}$ $(r=-0.219, p<0.01), S_{\mathrm{T}}(r=-0.205, p<0.01)$, shrub richness $\left(S_{\mathrm{S}}\right)(r=-0.174, p<0.01)$, and with other herbs $\left(r=-0.176, p<0.01 ; r=-0.185, p<0.01\right.$, and $r=-0.152, p<0.05$ for $S_{C}, H_{C}$, and $J_{C}$, respectively) (Table 3).

Considering architecture factors, style (AS) was significantly positively correlated with overall plant diversity $\left(H_{\mathrm{A}} ; r=0.148, p<0.05\right)$, evenness of trees $\left(J_{\mathrm{T}} ; r=0.176, p<0.01\right)$, and $S_{\mathrm{S}}(r=0.132$, $p<0.05)$. Architecture orientation (AO) was significantly positively correlated with $H_{\mathrm{A}}(r=0.170$, $p<0.01)$, and garden type (GT) was significantly positively correlated with total plants $(r=0.165$, $p<0.05$, and $r=0.167, p<0.05$ for $S_{\mathrm{A}}$ for $\left.H_{\mathrm{A}}\right), S_{\mathrm{S}}(r=0.212, p<0.01)$, and other herbs $(r=0.158$, $p<0.01$, and $r=0.141, p<0.01$ for $S_{\mathrm{C}}$ and $H_{\mathrm{C}}$, respectively) (Table 3 ).

\subsection{The Influence of Explanatory Variables on the Distribution of Plant Communities}

\subsubsection{Correlation Analysis of Explanatory Variables}

Figure 3 shows that there was a strong correlation among all variables, with different levels of statistical significance. Among the topography factors, PE was positively correlated with PS $(r=0.36$, $p<0.001)$, and negatively correlated with slope aspect (PSA) $(r=-0.27, p<0.001)$. Considering the architecture factors; style, height, orientation, layout type, and function (AS, AH, AO, AT, and AF, respectively) were positively correlated among them. AH was significantly positively correlated with AS $(r=0.79, p<0.001)$. Traditional buildings were generally $1-2$ floors and used for self-residence, while modern or combined buildings were at least $2-4$ floors and may be used for accommodation or public buildings. AO and AT were also significantly positively related to AS and AF. The orientation of buildings was greatly affected by the residents' personal wishes, while the homestay or public buildings always faced the main road, to be located easily. Considering all factors, PSA and PE were significantly positively correlated with $\mathrm{AH}(r=0.18, p<0.01$ and $r=-0.14, p<0.05$, respectively) and $\mathrm{AO}(r=0.30, p<0.001$ and $r=-0.20, p<0.01$, respectively), while PSA was significantly negatively correlated with GT $(r=-0.15, p<0.05)$, which indicated that the two topography factors had a certain impact on the way of building construction and utilization. 


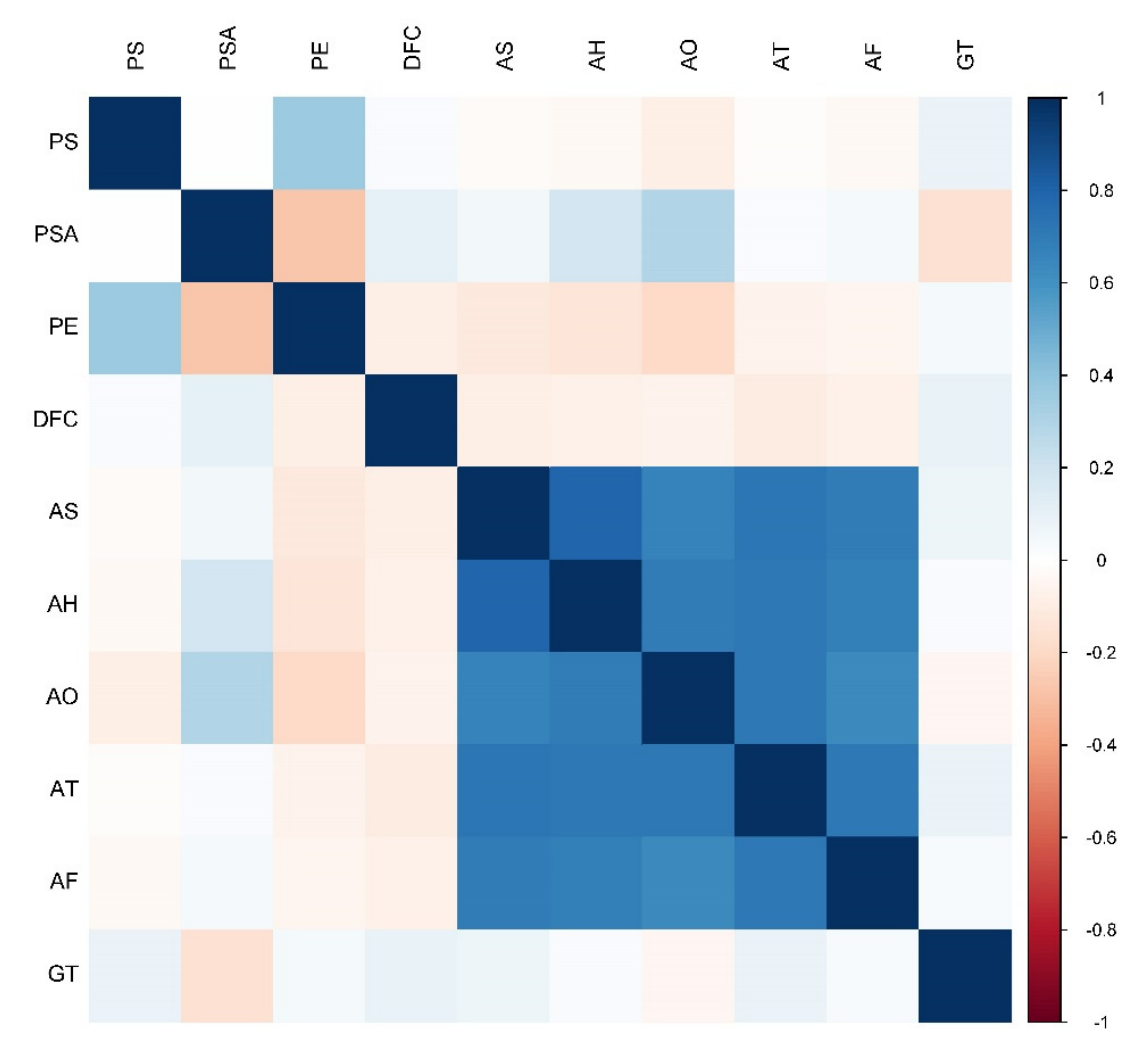

Figure 3. Spearman correlation diagram of environmental explanatory variables. (Different colors indicated different correlation coefficients).

\subsubsection{Redundancy Analysis}

The Monte Carlo test showed that all canonical axes were significant $(P<0.001)$, which indicated that RDA results were reliable and could explain the relationship between plant community distribution and environment, including topographic and architectural environment.

Table 4 shows that PSA, PE, AO and AT were significantly related to the first two canonical axes in the Monte Carlo tests. The total explanatory ability of plant distribution combining the first two axes was $49.85 \%$ (Axis $1=34.66 \%$, Axis $2=15.19 \%$ ). According to the final $R^{2}$ results, $P S A\left(R^{2}=0.080\right)$ and $\mathrm{PE}\left(\mathrm{R}^{2}=0.496\right)$ were the variables most significantly correlated with the plant communities, followed by AO $\left(R^{2}=0.034\right)$ and AT $\left(R^{2}=0.051\right)$. Other factors failed to explain the relationship between plant community distribution and environment (Figure 4).

Table 4. Correlation between explanatory variables and plant communities at Axis-1,2.

\begin{tabular}{ccccc}
\hline & RDA1 & RDA2 & $\mathbf{R}^{\mathbf{2}}$ & $\boldsymbol{P}$ \\
\hline PS & -0.96281 & -0.27016 & 0.0176 & 0.137862 \\
PSA & -0.08492 & -0.99639 & 0.0804 & $\mathrm{P}<0.001^{* * *}$ \\
PE & 1.00000 & 0.00276 & 0.4959 & $\mathrm{P}<0.001^{* * *}$ \\
DFC & 0.16032 & 0.98707 & 0.0054 & 0.527473 \\
AS & 0.85687 & -0.51553 & 0.0090 & 0.374625 \\
AH & 0.15544 & -0.98785 & 0.0250 & 0.069930. \\
AO & 0.15871 & -0.98733 & 0.0335 & $0.019980^{*}$ \\
AT & 0.80446 & -0.59401 & 0.0506 & $0.004995^{* *}$ \\
AF & 0.03879 & 0.99925 & 0.0286 & 0.054945. \\
GT & 0.06055 & 0.99817 & 0.0099 & 0.329670 \\
\hline
\end{tabular}

Test of significance of all canonical axes, $F=1.632, P<0.001^{* * *} ;{ }^{*} P<0.05 ;{ }^{* *} P<0.01 ;{ }^{* * *} P<0.001$. 


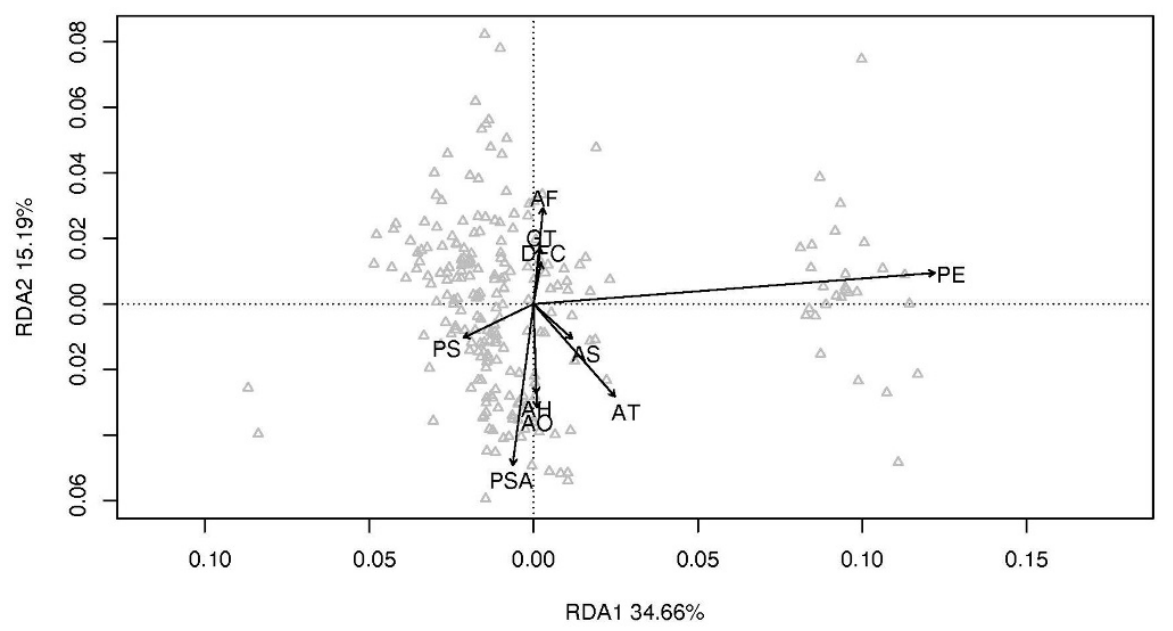

Figure 4. Redundancy analysis (RDA) between the plant communities and environmental factors of 227 samples in rural settlements of hilly area.

\section{Discussion}

\subsection{Selection of Dominant Species}

Plant selection preference was highly consistent among different settlements, with a certain degree of difference. Nevertheless, the dominant species can all satisfy the residents' demands, including food production, life, aesthetic, and social interaction. Most of the dominant trees and shrubs were native species, with only nine alien species, which resulted from the interference of higher planners, by bringing ornamental plants to enrich the plant landscape. Bamboo species were mainly economic species for shoots in Zhejiang Province. There were more alien species in the dominant species of herbs than in other plant types in each settlement unit, suggesting that the contribution and status of alien species of herbs were key in the human settlements.

Bamboo was popular among local residents, because it was palatable and convenient to eat for shoots when planted around the buildings. Coverage of Phyllostachys heterocycla occupied wide areas in the rural hills of Zhejiang Province. However, the income from the bamboo timber industry only accounted for $4.9 \%$ of the family's annual income in the study area (the average family income from bamboo timber was 5000 Chinese yuan per year, and the total annual income of the family 102,000 yuan), based on a survey. Thus, Phyllostachys heterocycla was not the main economic source, owing to the declined market-value of bamboo. Now, bamboo is mainly used for bamboo shoots. Dendrocalamus jianshuiensis, Phyllostachys nuda, and Phyllostachys propinqua contribute abundantly to the diversity of bamboo shoots in hilly areas, owing to their different shoot characteristics. In particular, Phyllostachys prominens and Phyllostachys nigra, which were just planted in a village at about 700-m elevation in the study area, can be used for timber, high-yield bamboo shoots, and as ornamental plants. Previous research showed that elevation has a significant impact on the growth and quality of bamboo shoots, and Phyllostachys prominens would be of high-quality and was good for the growth of bamboo crown when planted at high altitude areas [21-23]. In addition, ornamental bamboo species, such as P. nigra, Pseudosasa amabilis, and Bambusa multiplex were introduced by individual residents or the government to enrich the landscape, and were mainly planted in the courtyard interior or the background wall of special buildings with minor distribution scope, such as homestay, village committee, or commercial buildings.

As one of the "Beautiful towns in China", the planning activities introduced more alien species of herbs with outstanding ornamental and medicinal value, which were adaptable to the environment in the study area. The research showed that the main invasive plants in Zhejiang Province were herbs, which grow fast and have strong reproductive capacity [24]. Alien species were often considered to 
have a negative impact on local biodiversity, but research showed that interaction with alien species was neutral or even promoted native species [25], and alien species were even more dynamic and competitive than native species [26]. Alien plants had not reduced the diversity of native species and had a great contribution to the richness of herbs. Moreover, alien plants have become an important part of the settlements' ecological environment, imperceptibly brought social benefits. It was also an indispensable part of residents' life. Specifically, Conyza canadensis and E. annuus can be introduced from the surroundings through natural transmission, such as wind, water, and air flow. Solidago decurrens and Oxalis corniculata were introduced as ornamental plants, Talinum paniculatum as a medicinal plant. Veronica didyma and Plantago depressa were introduced through trading. New invasive herbs, such as Rumex acetosa, Myosoton aquaticum, Ranunculus japonicus, Brassica juncea, and Chrysanthemum coronarium, have spread in other regions, but no adverse spread effect has been seen in the study area [24].

\subsection{Relationship between Plant Community and Environment}

\subsubsection{Impact of Topographic Factors}

Research on the influence of topographic factors on the distribution of plant communities has been mainly carried out in forests' communities of the mountain areas, and the research showed that elevations, slopes, and slope aspects were dominant factors, influencing the distribution of forests communities. Several studies were conducted to explore the influencing factors, including environmental factors such as climate, soil, and topography, and their correlation mechanisms to the patterns of plant community distributions [16]. Altitudes and slope aspects have a significant impact on the growth of trees $[27,28]$, and topographic factors affect the growth and diversity of plants according to different soil properties [29]. Moreover, soil type, topography and spatial scale have a significant impact on the collective distribution of subtropical forest communities [30]. Furthermore, the vegetation in mountain areas is affected by several environmental factors, such as slope aspect, slope, and altitude, and the relationship curve between plant community diversity and altitude in different slope aspect was significantly different [31]. In addition, the slope aspect mainly affect sunshine and water distribution. Slope aspects have a significant impact on the undergrowth herbs in Phyllostachys heterocycla forests, and the plant diversity of the shady slope was larger than that of the sunny slope [32]. Slope and aspect are also important factors for the distribution of desertification herbs [33].

In this study, we focused on the human settlements in the subtropical low mountains and hills. Rural settlements were generally in the relatively flat areas and intensely disturbed by the human residential construction activities. RDA shows that the distribution patterns of plant communities were significantly affected by topography, even in the human-oriented settlement environments. In addition, the interpretation ability of elevation was the most outstanding under the interaction of multiple factors. In the study area, PE of 227 samples were between in areas with altitudes of 180 to $750 \mathrm{~m}$, and villages over $600 \mathrm{~m}$ belonging to high-altitude settlements (only accounting for $12.33 \%$ ). Moreover, hilly settlements were mainly distributed in relatively flat areas, where PE was below $400 \mathrm{~m}$. Although significantly lower than that of PE, the interpretation ability of PS influenced the distribution of illumination and water, further affecting the distribution pattern of plant communities, especially that of herbs species. PS affected the difficulty of village construction, so residents generally chose relatively flat areas for settlement construction and growth. In this study, $98 \%$ of PS was below $20^{\circ}$, dominated by gentle slope, and its influence on plant community distribution under the interaction of multiple factors was not obvious. Additionally, the distance from the settlements' center was not significantly related to plant communities, suggesting that plant community distribution in the hilly area did not show a specific pattern from the center to the outer edge of the settlements. Moreover, plant community distribution had no significant correlation with the geometric shape of the settlement, but was mainly affected by its elevation (PE) and slope aspect (PSA). 
According to RDA, PE played an important role in the distribution pattern of plant communities, under the interaction among multiple environmental factors. Moreover, correlation analysis of common indices of species diversity showed that PE was negatively correlated with $S_{\mathrm{A}}, S_{\mathrm{T}}, S_{\mathrm{B}}, S_{\mathrm{C}}, H_{\mathrm{B}}$, and $J_{\mathrm{B}}$. Disregarding the interaction among multiple factors, PSA had no significant correlation with diversity index, while PS had a significantly negative correlation with $S_{C}, H_{C}$, and $J_{C}$, suggesting that flat and gentle slopes were conducive to herbs growth and spread and can contain more herb species in the residential environment of hilly area. PS also had a significantly negative correlation with $S_{\mathrm{A}}, S_{\mathrm{T}}$, and $S_{\mathrm{S}}$, but had no significant impact on the indices of bamboo. Thus, in the bamboo villages from hilly areas, $H_{\mathrm{B}}$ was not subject to the topography factors in small-scale human settlements. In general, the topography factors affected the overall distribution pattern of plant communities, which included the distribution of shrubs and other herbs, but were less related to bamboo distribution.

\subsubsection{Impact of Human Residential Construction Activities}

The most intuitive and effective way to show the spatial form of villages is the space texture, including planar texture and facade texture. In this study, the planar texture includes building layout type and courtyard type, while the facade texture includes building height, number of floors, wall material, color, and roof form [34]. Wang Yun constructed a mathematical model to express the concept of spatial architectural distribution by three variables, i.e., coverage of single building, building angle, and distance between every two buildings [35]. The emergence of settlements generally does not have much mandatory planning, especially regarding the architectural relationship, shape, and orientation, which results in disordered and orderly interweaving relationships. This relationship is called "The Sociality of Space" by the British scholar Hillier. It includes many social and natural factors, such as production, way of life, social organization structure, geography, climate, and plant environment [36]. Based on morphology, Liu Peilin introduced the types, configuration forms, and distribution characteristics of residential buildings in detail [37]. Regarding architectural garden plant landscape, ethnobotany research especially focuses on the plant varieties demanded by residents, that affect the distribution pattern of the rural plant community [7,38]. In addition, garden plant varieties are closely related to the form of courtyard enclosure, architectural style, and architectural type manifested by human activities in settlements. In summary, the activities of residents in the settlement mainly involve private residence, and the state of living reflects humanities indices, such as needs of residents, age level, social level, economic level, and aesthetic preference. Human activities and demand preferences directly affect the surrounding plant environment. Therefore, it is inferred that the architectural attribute characteristics are closely related with the plant community environment.

The study of relationships between architecture and plants focused on those in cities, including vertical plant diversity such as green roofs and green walls (vertical corridors). Architectural surface (e.g., vertical walls and roof) is a special habitat that has a significant relationship with biodiversity. In this study, the architecture and courtyards of residential buildings also provide a certain growth space for ornamental and alien species that can reduce the gray barrier and help species spreading [39]. Generally, domestic research on settlement architecture is more extensive than that in overseas, involving from the single building structure to the spatial distribution of settlement architecture. However, research on the impact of settlement architectural attributes on plant communities is scarce. Therefore, this study mainly selected the planar texture of single building and its functional attributes, to explore the impact of human residential building activities on the distribution of plant communities.

The results supported the hypothesis that the architectural factors, such as architectural orientation and layout type (AT), which had a significant impact on plant community distribution patterns, have a certain explanatory ability for plant community distribution, while other architectural factors did not. Architectural orientation represents the front orientation of the single residence, which is rich and varied, owing to the residents' free choice in the study area. This reflects the residents' diverse willingness to construct residential buildings, with complex influencing factors. The preference in terms of orientation affects the surrounding plants and the distribution pattern of the whole plant 
community. In addition, AT was significantly related to the distribution pattern of plant communities, among them, detached buildings, lateral buildings, and " $\mathrm{L}$ "-shaped buildings accounted for about $74.79 \%, 11.97 \%$, and $12.82 \%$, while the three-section courtyard only accounted for $0.43 \%$. Relative analysis showed that the architectural orientation was significantly related to the overall diversity, tree evenness, and shrub richness. The construction of settlement buildings is different from that in the city, and it depends on the individual choice and regional characteristics of residents. Both architecture and plant environment serve the life of residents, especially the ornamental trees, which are mainly concentrated in the front of the building. The agricultural utilization plants are common on the side or back of the house. Therefore, the sunlit architecture is conducive to more ornamental plants. Ornamental trees can be selected in a wide range, such as all kinds of color-leaved shrubs. However, the regional agricultural plants are highly consistent, such as bamboo and fruit plants. The courtyard type reflects the residents' taste and garden planting preference, and is positively related to the overall, shrub, and herb richness, and the evenness of trees, shrubs, and grasses. Studies have shown that the courtyard has an outstanding contribution to plant diversity in the settlement, and its enclosure form has a significant impact on plant cultivation, e.g., full-enclosure garden means a larger capacity for plant species and green quantity, owing to plenty of space; a half-enclosure garden is mostly in the form of a low wall, and a non-enclosure garden is mostly the extended building space of cement ground, so the residents do not have the consciousness of space enclosure, i.e., the awareness about garden plant landscaping is weak, having a significant impact on the overall shrubs' and herbs' richness, but less on that of trees.

By comprehensively analyzing the effect of topographic and architecture factors on plant communities, it was found that no explanatory factors other than elevation had a significant effect on diversity and richness indices of bamboo plants. This may be due to the limited variety of bamboo plants. A total of 19 species of bamboo were investigated in the study area and most bamboo species were used for shoots. The ornamental bamboo species, such as Phyllostachys nigra and Pseudosasa amabilis, were rare and planted only in local areas around public buildings. Therefore, the number of species and functions involved were far less than those of trees, shrubs and herbs, and the selection of bamboo species was highly consistent, owing to the quality and taste of bamboo shoots. Bamboo was often planted in front or behind the house for the purpose of consuming bamboo shoots, and bamboo forests around the village were also a source of edible shoots. Bamboo species distribution was strongly uniform and less affected by environmental explanatory factors other than elevation.

Trees were the main part of the plant community in terms of quantity and volume. They were highly consistent in species selection and had weak responses to topographic and architecture factors. As opposed to this, the richness of shrubs and herbs were more affected by human activities. In particular, the contribution and impact of courtyard activities on the diversity of shrubs and herbs were apparent.

\subsection{Sustainable Development of Rural Settlements Environment}

Based on the characteristics of plant species and the diversity indices, the study found that plant communities were with high richness and wide coverage. The study area is a pioneer of Chinese beautiful countryside construction. However, many problems have emerged, including weak management and low control of tourism development. In contrast, the continuous development of tourism projects has led to crowded tourists during peak seasons, which also prompted the changes in the use of residential buildings that changed from private residence to accommodation, and catering to the tourists' aesthetic and demands. In particular, the street space is crowded out by a large number of accommodations, with poor air permeability, which seriously disrupts the self-organized properties of the settlements. Nevertheless, the settlements have been seriously commercialized, which has a positive impact on the economic life of residents, but a strong negative effect on the protection of traditional village culture and ecological landscape. Additionally, the ecological landscape planning still failed to fully respect the wishes of residents. In the course of our investigation and 
interviews, it was found that residents had a poor evaluation of the effect of plant landscape. For the rural plant community ecosystem, blindly emphasizing diversity is not the most effective solution to the development of ecological environment. It may lead to unnecessary plant landscaping, e.g., taking the village as a park for planning and design to attract tourists, interfering with the life of local residents. Ecological sustainability is the most important part of the development of the rural settlement environment, including the residents' economic production and living, tourists' recreational experience, regional ecological and cultural characteristics, and the sustainable development of rural natural environment [40]. In this study, the species' characteristics, diversity, and distribution of plant communities were analyzed by using ecological methods, such as diversity index calculation, redundancy analysis, and correlation analysis, and the basic characteristics of plant communities in hilly settlements were derived. We explored the mechanisms behind human activity effects on plant communities from the relationship among variables, and generated some inspiration for the construction of regional settlement plant environment to realize Chinese rural revitalization and the sustainable development of human settlements worldwide.

The impact of topography on the distribution of plant communities was significantly greater than that of human activities of residential construction, especially for hills or mountainous areas with complex topographic features. We should pay attention to the protection of original natural landscape, and need to explore a way that not only does not affect the economic benefits of residents, but also ensures the traditional ecological and cultural landscape of settlements, which is very necessary for residents' life and tourists' experience. Therefore, this study proposed to effectively control plant diversity and retain more characteristics of bamboo landscape, on the premise of respecting the production and living needs of local residents. The results of the investigation and interviews showed that the contribution of bamboo forests landscape is more effective than that of the disordered forests landscape and can also display the characteristics of the bamboo village in the study area. In addition, scientific management and control should be carried out for activities of residential construction, such as controlling the height of building layers, and repairing and maintaining traditional buildings, instead of demolishing and reconstructing. Moreover, we also encourage plant construction in the open garden space, realizing high sharing of private garden plant landscape, which not only maintains plant diversity but improves the diversity of plant landscape. Regarding public plant space, plants' arrangement should adapt to the change of topography and realize the continuation of the landscape, to avoid excessive fragmentation from the settlements' surrounding forests to the settlements' interior plant communities.

\section{Conclusions}

In this study, a total of 416 species of plants were investigated in 227 sample plots of 14 settlements, and the richness and diversity of plant communities were found to be relatively high. Both the topography and human activities had a certain impact on plant communities. The explanatory ability of topographic factors for plant communities was significantly higher than that of architectural factors, especially elevation and slope aspect, which had a significant impact on plant community distribution. Elevation had a significant correlation with the overall richness and evenness indices and the richness index of different plant types. among six architecture factors, architectural orientation and layout type had a significant impact on the distribution of plant communities, being significantly correlated with the evenness indices of trees, shrubs, and herbs.

In addition, RDA and correlation analysis results from diversity indices and environment factors revealed the distribution patterns and diversity characteristics of plant communities in the hilly areas and provided constructive suggestions for the sustainable development of this type of regional settlement. In future studies, more effective explanatory variables should be added, so as to study comprehensively the plant community distribution, and the study area should be expanded to mountainous basin archetypal settlements, to explore impact mechanisms and their differences between different types of settlements. 
Author Contributions: Z.W. analyzed data and drafted the manuscript. W.H., K.W., J.Z., X.W., participated in collecting the experiment data. C.W. and Z.J. was involved in the planning of the study and the designing of the work. The remaining authors contributed to refining the ideas, carrying out additional analyses and finalizing this paper. All authors discussed the results and revised the manuscript. All authors have read and agreed to the published version of the manuscript.

Funding: This work was supported by the Special Fund for Forestry Scientific Research in the Public Interest (No.201404301) and Project of Shenzhen Forest City Planning.

Conflicts of Interest: The authors declare no conflict of interest.

\section{References}

1. Chen, Z.; Liu, Y.; Feng, W.; Li, Y.; Li, L. Study on spatial tropism distribution of rural settlements in the Loess Hilly and Gully Region based on natural factors and traffic accessibility. J. Rural Stud. 2019, 1-8. [CrossRef]

2. Palmisano, G.O.; Govindan, K.; Loisi, R.V.; Sasso, P.D.; Roma, R. Greenways for rural sustainable development: An integration between geographic information systems and group analytic hierarchy process. Land Use Policy 2016, 50, 429-440. [CrossRef]

3. Jones, E.E. An analysis of factors influencing sixteenth and seventeenth century Haudenosaunee (Iroquois) settlement locations. J. Anthropol. Archaeol. 2010, 29, 1-14. [CrossRef]

4. Blanco, J.; Sourdril, A.; Deconchat, M.; Ladet, S.; Andrieu, E. Social drivers of rural forest dynamics: A multi-scale approach combining ethnography, geomatic and mental model analysis. Landsc. Urban Plan. 2019, 188, 132-142. [CrossRef]

5. Luzuriaga-Quichimbo, C.X.; del Barco, M.H.; Blanco-Salas, J.; Cerón-Martínez, C.E.; Ruiz-Téllez, T. Plant Biodiversity Knowledge Varies by Gender in Sustainable Amazonian Agricultural Systems Called Chacras. Sustainability 2019, 11, 4211. [CrossRef]

6. Mimet, A.; Kerbiriou, C.; Simon, L.; Julien, J.; Raymond, R. Contribution of private gardens to habitat availability, connectivity and conservation of the common pipistrelle in Paris. Landsc. Urban Plan. 2020, 193, 103671. [CrossRef]

7. Berkowitz, B.N.; Medley, K.E. Home Gardenscapes as Sustainable Landscape Management on St. Eustatius, Dutch Caribbean. Sustainability 2017, 9, 1310. [CrossRef]

8. Gao, C.; Cheng, L.; Iqbal, J.; Cheng, D. An Integrated Rural Development Mode Based on a Tourism-Oriented Approach: Exploring the Beautiful Village Project in China. Sustainability 2019, 11, 3890. [CrossRef]

9. Wu, Y.; Wang, H.; Wang, Z.; Zhang, B.; Meyer, B.C. Knowledge Mapping Analysis of Rural Landscape Using CiteSpace. Sustainability 2020, 12, 66. [CrossRef]

10. Li, Q.; Wumaier, K.; Ishikawa, M. The Spatial Analysis and Sustainability of Rural Cultural Landscapes: Linpan Settlements in China's Chengdu Plain. Sustainability 2019, 11, 4431. [CrossRef]

11. Mao, Y.; Liu, Y.; Wang, H.; Tang, W.; Kong, X. A Spatial-Territorial Reorganization Model of Rural Settlements Based on Graph Theory and Genetic Optimization. Sustainability 2017, 9, 1370. [CrossRef]

12. Kobayashi, Y.; Koike, F. Separating the effects of land-use history and topography on the distribution of woody plant populations in a traditional rural landscape in Japan. Landsc. Urban Plan. 2010, 95, $34-45$. [CrossRef]

13. Ma, K.; Tang, X.; Ren, Y.; Wang, Y. Research on the Spatial Pattern Characteristics of the Taihu Lake "Dock Village" Based on Microclimate: A Case Study of Tangli Village. Sustainability 2019, 11, 368. [CrossRef]

14. Wu, X.; Luo, J.; Chen, J.; Li, B. Spatial Patterns of invasive alien plants in China and its Relationship with environment and Anthroplogical factors. J. Plant Ecol. 2006, 30, 576-584.

15. Xu, W.; Bao, Q. The Planning and Design Practice of New Countryside Landscape-The Restructuring of Countryside Landscape of Shanchuan Village, Shanchuan Township in Anji County. Chin. Landsc. Archit. 2010, 26, 80-82.

16. Liu, G.; Huang, Y.; Wang, Q.; Xing, Y. Effects of Environmental Factors on Plant Species Diversity. Res. Prog. Chin. Agric. Sci. Bull. 2018, 34, 83-89.

17. Lou, C.; Zhu, G. Study on Ecological Regionalization for Bamboos in Zhejiang Province. J. Zhejiang For. Coll. 2007, 24, 741-746.

18. Pu, X. Study on the Quantitative Method of the Plane Forms of Traditional Rural Settlements; Southeast University Press: Nanjing, China, 2013.

19. Zhang, J. Quantitative Plant Ecology; Science Press: Beijing, China, 2011; p. 5. 
20. Borcard, D.; Gillet, F.; Legendre, P. Numerical Ecology with R; Springer: Berlin, Germany, 2018; Volume 4.

21. Shi, J.; Chen, S.; Guo, Z.; Gao, P. Influence of Altitudes on Quality of Phyllostachys prominens Shoot. For. Res. 2018, 31, 113-117.

22. Shi, J. Influence of Altitude on Culm Form, Crown, Phylliform of Phyllostachys prominens. J. Northeast. For. Univ. 2018, 46. [CrossRef]

23. Shi, J.; Gu, R.; Chen, S. The Effect of Altitude on the Protein Nutritional Value of Phyllostachys prominens Bamboo Shoots. Agric. Univ. Jiangxiensis 2019, 41, 308-315.

24. Yan, X.; Shou, H.; Ma, J. The Alien Invasive Plants in Zhejiang Province, China. Plant Divers. Resour. 2014, 36, 77-88.

25. Guerin, G.R.; Martin-Fores, I.; Sparrow, B.; Lowe, A.J. The biodiversity impacts of non-native species should not be extrapolated from biased single-species studies. Biodivers. Conserv. 2018, 27, 785-790. [CrossRef]

26. Atyosi, Z.; Ramarumo, L.J.; Maroyi, A. Alien Plants in the Eastern Cape Province in South Africa: Perceptions of Their Contributions to Livelihoods of Local Communities. Sustainability 2019, 11, 5043. [CrossRef]

27. Zhu, G.; Niklas, K.J.; Li, M.; Sun, J.; Lyu, M.; Chen, X.; Wang, M.; Zhong, Q.; Cheng, D. “Diminishing Returns” in the Scaling between Leaf Area and Twig Size in Three Forest Communities Along an Elevation Gradient of Wuyi Mountain, China. Forests 2019, 10, 1138. [CrossRef]

28. Lu, A. Analysis of Growth Effect of Camellia nitidissma Under Different Slope Positions and Slope Directions. J. Green Sci. Technol. 2019, 201-203. [CrossRef]

29. Wang, C.; Lai, X.; Zhu, Q.; Michael, J. Castellano and Guishan Yang. Soil Type, Topography, and Land Use Interact to Control the Response of Soil Respiration to Climate Variation. Forests 2019, 10, 1116. [CrossRef]

30. Li, Y.; Bin, Y.; Xu, H.; Ni, Y.; Zhang, R.; Ye, W.; Lian, J. Understanding Community Assembly Based on Functional Traits, Ontogenetic Stages, Habitat Types and Spatial Scales in a Subtropical Forest. Forests 2019, 10, 1055. [CrossRef]

31. Xu, Y.; Chen, Y.; Li, W.; Fu, A.; Ma, X.; Gui, D.; Chen, Y. Distribution pattern and environmental interpretation of plant species diversity in the mountainous region of Ili River Valley, Xinjiang, China. Chin. J. Plant Ecol. 2010, 34, 1142-1154.

32. Yang, J. The Study of Plant Community Structure and Composition of Moso Bamboo Forests under Multi-Environment Gradients; Beijing Forestry University: Beijing, China, 2011.

33. Zhao, P.; Qu, J.; Xu, X.; Tang, J.I.; Han, Q.; Xie, S.; Wang, T.; Lai, J. Study on the characteristic of sandy alpine grasslands and its relationship between plant distribution and microtopography in the source regions of Yangtze River. Acta Ecol. Sin. 2019, 39, 1-11.

34. Tong, L. Parametric Analysis and Reconstruction of Villages' Spatial Texture and its Planning Application Research; Zhejiang University: Zhejiang, China, 2016.

35. Wang, Y. Space Concept in Traditional Settlement Structure; China Architecture \& Building Press: Beijing, China, 2016; Volume 7.

36. Zhu, W. Study of Village Settlement Space in Northern Zhejiang Basis on Geography; Zhejiang University: Zhejiang, China, 2009.

37. Liu, P. Landscape and Gene of Homeland-Deep Interpretation of Gene Map of Traditional Settlement; Landscape Commercial Press: Beijing, China, 2014; Volume 1.

38. Schneider, A.; Strohbach, M.; App, M.; Schröder, B. The 'GartenApp': Assessing and Communicating the Ecological Potential of Private Gardens. Sustainability 2020, 12, 95. [CrossRef]

39. Mayrand, F.; Clergeau, P. Green Roofs and Green Walls for Biodiversity Conservation: A Contribution to Urban Connectivity? Sustainability 2018, 10, 985. [CrossRef]

40. Cong, L.; Zhang, Y.; Su, C.-H.J. Ming-Hsiang Chen and Jinnan Wang. Understanding Tourists' Willingness-to-Pay for Rural and scape Improvement and reference Heterogeneity. Sustainability 2019, 11, 7001. [CrossRef]

(C) 2020 by the authors. Licensee MDPI, Basel, Switzerland. This article is an open access article distributed under the terms and conditions of the Creative Commons Attribution (CC BY) license (http://creativecommons.org/licenses/by/4.0/). 